\title{
PRÁTICAS EDUCATIVAS DE FAMÍLIAS NEGRAS E RELAÇÕES ÉTNICO- RACIAIS: UMA EXPERIÊNCIA EM FORMAÇÃO DE PROFESSORES
}

\author{
EDUCATIVE PRACTICES OF BLACK FAMILIES AND ETHNIC-RACIAL RELATIONS: AN \\ EXPERIENCE IN TEACHER TRAINING
}

\section{PRÁCTICAS EDUCATIVAS DE FAMILIAS NEGRAS Y RELACIONES ÉTNICO-RACIAL: UNA EXPERIENCIA EM LA FORMACIÓN DEL PROFESORADO}

\author{
Edna Martins \\ Renata Marcilio Candido
}

\section{RESUMO}

As práticas educativas familiares têm influência direta nos processos de formação de identidade racial das crianças negras, assim como norteiam os modos como essas questões são vivenciadas nas interações sociais em contextos diversos. Esse trabalho descreve uma experiência com estudantes de um curso de formação inicial de professores de uma universidade pública da Grande São Paulo. Centrada no estudo de referenciais teóricos que versam sobre socialização primária e identidade no contexto das relações étnico-raciais, tal experiência buscou iniciar os estudantes em um projeto de iniciação à pesquisa. Com o objetivo de compreender como ocorrem as práticas educativas de famílias negras com relação a socialização de suas crianças, a partir de metodologia qualitativa, o trabalho contou com dois grupos de alunos que realizaram entrevistas com 12 famílias da classe trabalhadora. Os dados analisados indicam que as práticas educativas da maioria das famílias negras entrevistadas incluem ações que se referem às relações entre cor/raça. Concluiu-se que tal experiência reafirma a relevância da inclusão de ações de pesquisa nos programas de ensino dos cursos de formação de professores, principalmente nas interfaces entre a educação científica e a questão das relações étnico-raciais, tendo em vista a formação de profissionais empenhados no trabalho de combate à discriminação racial.

PALAVRAS-CHAVE: Afro-brasileiros. Família. Políticas públicas em educação. Conteúdos da formação de professores. Práticas educativas.

\begin{abstract}
Family educational practices have a direct influence on racial identity formation processes of black children, and guide the ways in which those issues are experienced in social interactions in different contexts. This paper describes an experience with students from an initial training course for teachers of a public university in São Paulo. Focused on the study of theoretical frameworks that deal with primary socialization and identity in the context of ethnic and race relations, this experiment sought to introduce students in an initiation to research project. With the object of understanding how occur the educational practices of black families regarding the socialization of their children, from a qualitative methodology, the work included two groups of students who conducted interviews with 12 families of the working class. The data analyzed indicate that the educational practices of most black families interviewed include actions that relate to the relationship between color / race. It was concluded that this experience reaffirms the importance of the inclusion of research activities in educational programs of teacher training courses, especially at the interfaces between science education and the issue of ethnic and race relations, in view of the formation of committed at work to combat racial discrimination.
\end{abstract}

KEYWORDS: African-Brazilians. Family. Public policies in education. Content of teacher education. Educational practices. 


\section{RESUMEN}

Las prácticas educativas familiares tienen una influencia directa en los procesos de formación de la identidad racial de los niños negros, así como guían las formas de como esas cuestiones son vividas en las interacciones sociales en diferentes contextos. Este artículo describe una experiencia con estudiantes de un curso de formación inicial para profesores de una universidad pública en el gran São Paulo. Centrado en el estudio de referencias teóricas que tratan sobre la socialización primaria y la identidad en el contexto de las relaciones étnico-raciales, tal experiencia buscó introducir a los estudiantes en un proyecto de iniciación a la investigación. Con el objeto de comprender como suceden las prácticas educativas de las familias negras en relación a la socialización de sus hijos, desde una metodología cualitativa, el trabajo comprendió dos grupos de estudiantes que realizaron entrevistas a 12 familias de la clase obrera. Los datos analizados indican que las prácticas educativas de la mayoría de las familias negras entrevistados incluyen acciones que se refieren a la relación entre el color / raza. Se concluyó que tal experiencia reafirma la importancia de la inclusión de las actividades de investigación en los programas educativos de los cursos de formación del profesorado, especialmente en las interfaces entre la educación científica y la cuestión de las relaciones étnico-raciales, teniendo en cuenta la formación de profesionales comprometidos en el trabajo de combate a la discriminación racial.

PALABRAS ClAVE: Afro-brasileños. Familia. Políticas públicas en educación. Contenido de la formación docente. Prácticas educativas.

\section{INTRODUÇÃO}

O ser humano pode ser compreendido como um organismo geneticamente social. A partir da análise da filogênese de nossa espécie, inegavelmente a família ${ }^{1}$ tem constituído elemento essencial para a evolução, preservação, manutenção, permanência e emancipação dos membros de uma mesma constituição biológica, social e culturalmente distinta de tantas outras que habitam o planeta. Analisando a ontogênese humana, observa-se a importância da mediação de membros mais experientes (mães, pais e outros cuidadores) para a sobrevivência das crianças, principalmente nos primeiros anos de desenvolvimento. A espécie humana é, sem dúvida, aquela em que os filhotes dependem invariavelmente de adultos por longo período de tempo (VYGOTSKY, 1995).

Desde que os bebês humanos nascem começam uma grande jornada de socialização, que em primeiro lugar se dá no seio da família de origem em contato com seus outros significativos (pai, mãe, irmãos ou outras pessoas que exercem a função de cuidadores). Nessa primeira escalada pelo mundo social, chamada de socialização primária, as crianças vão apreendendo valores e normas sociais e internalizando a cultura do contexto no qual os outros significativos vivem. Atrelado a esse momento inicial, consecutivamente ocorre o processo de socialização secundária, no qual os humanos passam a se socializar com os outros externos ao sistema familiar como os indivíduos da escola, da vizinhança, da igreja

\footnotetext{
${ }^{1}$ Em distintos contextos históricos, o conceito de família possuiu diferentes configurações, desde os grupos mais numerosos (aldeiais, tribos) nos quais todos eram responsáveis pelos cuidados e educação dos menores, passando pelo modelo tradicional burguês (família nuclear), atualmente trabalhamos com os mais diversos arranjos que se organizam para permitir o suporte necessário ao pleno desenvolvimento do ser humano (Nogueira, Romanelli, Zago, 2011; Lahire, 1997).
} 
dentre muitos outros. Passo a passo, vão tomando contato com diversos discursos sociais e construindo percepções diferentes daquelas que adquiriu na socialização primária (BERGER E LUCKMAN, 1983).

Neste conjunto de inserções e interações do gênero humano no mundo social é que se forjam as identidades. Como conceito chave para a compreensão das relações humanas, a constituição da identidade de um indivíduo pressupõe uma interação com outros de sua espécie. O reconhecimento, ou a ideia que um sujeito faz de si mesmo, é mediada pelo outro social, portando não se pode construir uma identidade no isolamento, pois trata-se de uma categoria que pressupõe o diálogo consigo mesmo e com os outros e, a transformação durante o processo de existência humana (CIAMPA, 1987; PAIVA, 2007; PINTO; FERREIRA, 2015).

Historicamente, as configurações de família, assim como formas de educação e cuidados com os filhos foram se modificando. Mudanças políticas e histórico-culturais marcaram a complexidade da formação da família negra, demonstrando o quanto tal população absorveu durante longos anos elementos como sofrimento, exclusão e mazelas sociais (ARAUJO; CAMARGO, 2015). Com relação à socialização primária de crianças negras, uma das primeiras pesquisas a tratar da questão, foi o trabalho de Cavalleiro (2000) que enfatizou o silenciamento da família e da escola para lidar com assuntos ligados a cor/raça com as crianças pequenas. Sobre esse assunto Gomes (2006) afirma que:

\begin{abstract}
Quanto mais aumentam as vivências da criança negra fora do universo familiar, quanto mais essa criança ou esse adolescente se insere em círculos sociais mais amplos como é o caso da escola, mais se manifesta a tensão vivida pelos negros na relação estabelecida entre a esfera privada (vida familiar) e pública (relações sociais mais amplas) (p. 212).
\end{abstract}

A construção de identidade e reconhecimento étnico-racial se dá, portanto, na interação com o outro nos processos de socialização das crianças, seja no sistema familiar em que elas constroem as primeiras ideias sobre si e sobre aqueles que a rodeiam ou em outros contextos como a instituição escolar. Antes de irem para a escola, as crianças já construíram uma gama de conhecimentos e internalizaram vários discursos socializadores. Dentre os muitos acessos ao mundo social que as crianças realizam ainda no seio da família, destaca-se o contato com o discurso televisivo. Lewis e Nascimento (2013) apontam que os discursos sociais, e sobretudo, socializantes, que são veiculados pelos programas de televisão que as crianças têm acesso ainda no seio da família quando bem pequenas, são imperativos na reprodução de lugares raciais hierarquizados. As autoras afirmam que, à medida que tais meios interferem nos processos de socialização, podem ter impacto direto na construção da identidade racial das crianças, especialmente em famílias que compõem a população negra.

De um modo geral, assim como constatado por Gebara e Gomes (2014) também parece haver um "intrigante silêncio" por parte da literatura científica a respeito da temática família negra contemporânea no Brasil. As autoras apontam que são raras as produções antropológicas/sociológicas sobre o tema, demonstrando a invisibilidade racial das famílias 
nos estudos que abordam o tema e "ao não se referir ao pertencimento étnico-racial das famílias abordadas, os estudos clássicos e contemporâneos nos levam a pensar que as discussões realizadas podem ser generalizadas para todos os grupos sociais e étnico-raciais". (GEBARA; GOMES, p. 129)

Considerando a escassez de produções científicas que possam dar foco e visibilidade as especificidades da família negra e as maneiras pelas quais procuram educar suas crianças o presente trabalho busca relatar a experiência de formação de professores em pesquisa, com uma turma de estudantes do Curso de Pedagogia considerando as seguintes questões: Quais as práticas educativas utilizadas por famílias negras em seu cotidiano nos processos de socialização de seus filhos e filhas no que concerne as questões étnico-raciais? Em que medida as questões relacionadas às relações étnico e raciais são consideradas por mães negras de camadas populares nos processos educativos de suas crianças?

Dada a tônica deste trabalho, é importante ressaltar, como aponta Verrangia (2015) a relevância da inclusão nos programas de ensino e pesquisa nas ciências humanas as interfaces entre a educação científica e a educação das relações étnico-raciais, tendo em vista a formação de professores e pesquisadores no trabalho de combate à discriminação racial tão presente nas escolas brasileiras.

\section{METODOLOGIA: AÇÕES NA DISCIPLINA "PRÁTICAS PEDAGÓGICAS PROGRAMADAS"}

Um dos objetivos da disciplina Práticas Pedagógicas Programadas que acontece semestralmente no curso de Pedagogia da Universidade Federal de São Paulo - UNIFESP é a realização da iniciação dos alunos ao mundo da pesquisa científica, além de buscar desenvolver momentos de aprendizagem que atentem para a articulação entre os estudos teóricos de vários campos do saber e as práticas educativas. A escolha da disciplina é feita pelos alunos, pois várias linhas de trabalhos são ofertadas pelos professores do curso a cada início de semestre. Além de encontros na universidade, a disciplina prevê que os estudantes realizem pesquisa de campo em locais específicos de cada linha de trabalho, a partir da orientação do professor responsável. Com uma carga horária de 40 horas, as turmas são formadas em grupos pequenos de 10 a 12 alunos no máximo.

O trabalho desenvolvido na disciplina segue um calendário de encontros semanais nos quais os estudantes realizam estudos teóricos e são orientados para a construção de instrumentos de pesquisa como questionários, roteiros de entrevistas, dentre outros e, em alguns casos, a ida a espaços específicos para a realização de pesquisas de campo que resultam em produtos que oportunamente são divulgados em um evento semestral que reúne várias linhas de trabalho na Universidade. Muitas linhas e estudos transformam-se em projetos de pesquisas e tendem a ter continuidade, destas emergem projetos mais elaborados envolvendo outros programas e orientações no curso de formação de professores. 
Outro objetivo da disciplina é o de inserção dos estudantes de Pedagogia em contextos nos quais são desenvolvidas práticas pedagógicas diversas no sentido de conhecerem as várias possibilidades de trabalho do pedagogo e as diversas trajetórias profissionais que ocorrem em instituições não escolares, tais como em hospitais, prisões, ongs, abrigos, empresas dentre outros. Há também a intenção de que os estudantes possam conhecer práticas educativas formais e informais realizadas nos mais diversos contextos, buscando favorecer a compreensão dos modos de educar em sua multideterminação.

A linha de trabalho "Práticas educativas familiares e as questões étnico-raciais" oferecida aos estudantes do curso de Pedagogia seguiu o calendário semestral de encontros presenciais e buscou possibilitar a iniciação à pesquisa a partir de um programa de discussão da temática em suas intersecções com a família e a escola. A pesquisa desenvolvida pelos estudantes objetivou realizar um levantamento de dados sobre as práticas educativas de famílias negras e as questões relacionadas à socialização primária, identidade negra e relações com a escola e a sociedade.

O desenvolvimento da pesquisa ocorreu apoiado em trabalhos teóricos que foram fundamentais para que a maioria dos estudantes, que tinham tido pouco ou nenhum acesso aos trabalhos sobre as questões relacionadas a raça/cor, pudessem acompanhar as discussões. Num primeiro momento foi pedido aos alunos que fizessem suas autodeclarações de cor/raça, espaço importante para a ocorrência do diálogo aberto e debate sobre a problemática racial na sociedade brasileira. Esta oportunidade possibilitou aos estudantes algumas reflexões sobre suas próprias identidades e a forma como viam a questão do ser negro ou branco em suas relações com o mundo da família, da escola e da universidade.

Em encontros subsequentes foram realizadas discussões teóricas de obras que versavam sobre a compreensão do conceito de socialização primária, assim como as práticas educativas de famílias negras e seu papel no desenvolvimento da identidade. Para tanto, foram utilizados trabalhos de pesquisas como os de Martins e Geraldo, (2013); Cavalleiro, (2000); Frankllin Ferreira e Camargo (2011). No bojo das discussões também foram trabalhados artigos que discutiam em seus resultados de pesquisas (Castro; Abramovay, 2006; Martins; Santos; Colosso, 2013) como a discriminação contra a população negra é vivenciada cotidianamente desde a mais tenra idade em espaços como o da escola.

Após a leitura e discussão dos textos fundamentais, deu-se início ao processo de preparação para ida a campo. As discussões no grupo envolveram a construção de um roteiro semiestruturado de questões que deveriam ser realizadas junto às famílias que participariam da pesquisa. Esse foi um momento bastante rico, pois os estudantes puderam trazer perguntas relativas às suas próprias trajetórias e histórias familiares que perpassaram as suas vidas de filhos de negros/brancos, numa profunda descoberta do processo de construção de suas identidades em um espaço-tempo determinado. 


\section{O TRABALHO DE CAMPO: OUVINDO AS FAMÍlLIAS NEGRAS SOBRE SUAS PRÁTICAS EDUCATIVAS}

A partir do aprofundamento sobre a temática e a construção do instrumento de pesquisa, os alunos puderam fazer um pré-teste em que utilizaram um roteiro semiestruturado realizando pequenas entrevistas entre eles e, recebendo orientação sobre tal procedimento. Assim, organizaram-se para o trabalho de coleta de dados considerando o objetivo central de investigar como famílias negras desenvolvem práticas educativas no que se refere à educação, identidade e valorização das questões pertinentes a cor e a raça.

Ao todo foram entrevistadas 12 famílias escolhidas pelos estudantes. Os critérios de seleção exigiam que os entrevistados se autodeclarassem pardos ou negros e tivessem filhos com idades entre 05 e 15 anos e que aceitassem voluntariamente participar da pesquisa. Todas as famílias escolhidas tinham de um a três filhos que estudavam em escola pública. Apenas uma das entrevistadas havia concluído o ensino superior, enquanto o restante tinha cursado o ensino médio completo. As entrevistas ocorreram nas residências das famílias ou nas escolas das crianças e foram todas gravadas em áudio com a autorização dos entrevistados que assinaram o termo de consentimento livre e esclarecido.

Após a realização do trabalho de campo todas as entrevistas foram transcritas na íntegra e lidas no grupo para a identificação dos detalhes e nuances das falas. A organização dos dados se deu de maneira que todos os participantes da disciplina pudessem ter acesso às informações obtidas. Passo a passo e em conjunto, foram sendo construídas as categorias de análise com base nos objetivos do trabalho. Esse foi um dos momentos mais ricos das reuniões entre as professoras e os estudantes, que puderam relatar pormenores de suas abordagens junto às famílias entrevistadas, mostrando-se curiosos para a exposição de cada resposta dada às questões abordadas nas entrevistas.

A partir da exploração pelo grupo das respostas mais frequentes dos entrevistados, obtidas sobretudo, pelo modo como foi organizado o roteiro semiestruturado de entrevista, ocorreu a construção das seguintes categorias de análise: Autodeclaração de cor/raça; Percepção sobre discriminação racial na escola; Práticas educativas raciais na escola; Apelidos no ambiente escolar; Diálogo sobre as questões raciais com os filhos; O cabelo como símbolo da identidade negra; Influência da televisão na educação da criança negra e Brinquedos para a criança negra.

\section{DISCUSSÃO DOS RESULTADOS: COMPREENDENDO AS PRÁTICAS EDUCATIVAS DAS FAMÍLIAS}

Antes de prosseguir, é importante ressaltar que se entende aqui por práticas educativas familiares, as expressões de ações de solicitude apresentadas continuamente no cotidiano da família ao longo das interações entre seus membros, sobretudo aquelas que contemplam a 
possibilidade dos mais jovens poderem construir e apropriar-se de conhecimentos, práticas sociais e hábitos que permitam a vida em sociedade, tal como apontado por Zsymanski (2004). Considera-se também a conceituação de Bernard Lahire (2004), que caracteriza tais práticas a partir de organizações familiares que valorizam e incentivam o trabalho realizado na e pela escola em ações como: ouvir os relatos de seus filhos no que se refere ao cotidiano escolar, fazer questionamentos sobre as atividades escolares de forma bastante interessada, permitir tempo e espaço para a realização dos aprendizados extra-escolares, dentre outros. A partir dessa compreensão, o momento de análise e discussão dos dados pelos alunos significou uma importante oportunidade de compreensão da temática ainda pouco abordada nos cursos de formação de professores. Os pequenos grupos de trabalho que compunham cada turma (10 alunos no máximo) possibilitaram um acompanhamento cuidadoso dos dados trazidos por cada dupla de estudantes.

Com relação a categoria "autodeclaração de cor/raça", discutiu-se longamente sobre as dificuldades das pessoas e dos próprios estudantes em se colocarem diante de suas identidades raciais e de saberem com convicção a sua cor. Dentre as ponderações, foi apontado que a categoria cor/raça indica uma diferença fenotípica e social percebida como imediata que distingue um indivíduo do outro e, em geral, implica na atribuição de estereótipos a determinado grupo de pertença. A autodeclaração de cor/raça relaciona-se diretamente com a identidade e tem sua confirmação ou negação a partir do olhar do outro, o que em alguns casos, pode determinar uma incongruência entre o reconhecimento que uma pessoa tem de si mesma e a forma como o outro a reconhece. É possível que ao fazer a autodeclaração o indivíduo busque identificação em elementos pertencentes ao seu grupo sociocultural de origem ou ainda, em sua ancestralidade, além de características relacionadas a sua aparência física.

Considerando a contradição presente nas relações raciais no Brasil e, que a identidade é construída na relação com o outro, os relatos dos estudantes sobre a insegurança de seus entrevistados $^{2}$ para se perceberem como negros/pardos ou a utilização do termo adequado para lidar com a questão da cor/raça foram comuns. Nomenclaturas para definição de cor tais como "moreninha", "escurinho", "marronzinha", "afrodescendente", "tipo assim que nem eu"; "cor mais escura"; "café com leite" foram as mais relatadas pelo grupo. Uma das alunas declarou sobre a sua entrevistada:

Ao realizar a entrevista, percebi que falar sobre questões étnico-raciais causa grande incômodo, pois em alguns momentos minha entrevistada hesitava falar quando era questionada, além de ter se declarado negra no decorrer da entrevista, mas no início, quando perguntei havia se declarado parda. (Relatório de Rosângela/branca)

\footnotetext{
${ }^{2}$ Todos os nomes apresentados são fictícios para garantir o sigilo das informações.
} 
A atitude considerada de maior "consciência" acerca do autoconceito sobre a cor/raça foi identificada por outros estudantes como é o caso de uma entrevistada por Mariele (aluna negra) que faz o seguinte relato:

No início da entrevista, quando interrogada sobre a cor de sua pele, ela mais do que depressa e com um enorme sorriso diz que é negra e tem muito orgulho disso, embora por diversas vezes, presenciou piadas de muito mau gosto sobre a cor preta”. Em outro relato a entrevistada diz o seguinte: "Eu sou negra, mas meus sete filhos são brancos...

Num outro caso, a mãe relata a dificuldade de lidar com a cor de suas duas filhas e os modos como o tema é tratado em família:

A Nélia se vê como negra, sim. Agora, a Graça já fica em dúvida, por ser mais clara. Ela fala "Mãe, eu sou negra? Sou parda? Sou morena? ", aí meu marido até brinca com ela "Não, filha, você é da cor da sua avó: cor de burro quando foge. " Por ser mais clara, ela fica confusa. (Maria, 47 anos)

Sobre essa temática, houve no grupo um momento de reflexão no qual os estudantes apontaram as suas próprias dificuldades em autodeclararem a sua raça/cor. Foram trazidos apontamentos teóricos como os de Osório (2003) e Piza e Rosemberg (1999) que discutem os critérios de auto declaração dos censos demográficos brasileiros. Os estudantes concordaram que no Brasil por conta da miscigenação o critério de auto identificação é confuso e muitas vezes a auto definição depende do olhar do outro. É como se uma autoimagem dependesse de classificação social deixando explícito a dificuldade das pessoas em nomear a própria cor/raça, bem como ouvir, opinar e debater sobre identidade étnico-racial. Quando os estudantes e os entrevistados foram questionados sobre a própria cor/raça, assinalou-se uma nova percepção de tal classificação, manifestando-se até mesmo um certo constrangimento. Tal fato, pode ser decorrente da opressão histórica que marca a relação entre os brancos e não-brancos no país e pelos desdobramentos ocorridos quando um indivíduo tem plena consciência de sua própria raça/cor.

Os dados sobre a percepção das famílias sobre o trabalho de orientação da escola no que tange a educação para as relações étnico-raciais corroboraram as investigações estudadas sobre a temática nos trabalhos de Castro; Abramovay, (2007) e Cavalleiro, (2000) que trouxeram subsídios teóricos para que os estudantes compreendessem o quanto os docentes encontram-se despreparados para enfrentar situações de racismo e outras relacionadas ao pertencimento étnico-racial das crianças no contexto escolar. Nessa direção os relatos trazidos pelos estudantes a partir das entrevistas com as mães de crianças negras, dão conta de que comumente os seus filhos se queixavam da forma como eram tratados por alguns de seus colegas na escola, afirmando serem hostilizados com xingamentos e apelidos. As famílias também denunciaram a forma evasiva com que a instituição escolar trata do tema e a falta de preocupação de alguns professores com situações de discriminação racial. Dentre os apelidos mais citados pelas mães, estão: "macaco", "fillho de Pelé”, "neguinho", "cabelo de pixaim", "gorila", "macaca chita", "pretinho", "urubu" e "saci”. 
Outros relatos vinham na contramão do reconhecimento da discriminação racial na escola e num processo de negação defendiam a tese de que tais xingamentos tratavam-se apenas de "brincadeiras" entre os alunos.

Olha, vou ser sincera, nunca vi nenhum aluno ser maltratado por professores, colegas, diretores... Vejo "tiração de sarro" só entre os colegas, como "ah negão", “oi branquelo”... Mas não acredito que isso seja um tratamento diferente... Apenas apelidos entre colegas. (...) são brincadeiras de "ah seu negão”, "nutella”, etc., Mas tudo entre amigos. (Lúcia, 48 anos)

Com relação à percepção das famílias sobre discriminação racial na escola, houve por parte de algumas famílias em princípio a negação de tais acontecimentos, contudo as que disseram que o(a) filho(a) nunca havia sofrido discriminação conhecia alguma história para contar sobre esse assunto. Neste sentido, destacamos a fala de Néia, uma das entrevistadas, sobre um caso de sua família no qual uma prima foi discriminada pelo seu pertencimento racial, em uma escola educação infantil.

(...) eu tenho uma prima que estuda na creche, que ela é bem negra, com a pele bem negra e o cabelo bem crespo e ela sofreu preconceito por causa do cabelo. As crianças começaram a rir e ela não queria mais ir com o cabelo de trancinha porque era duro e as crianças faziam piadinha. E ela só tem 4 anos. (Néia, 38 anos)

Com relação à questão, os estudantes reconheceram que os cursos de formação oferecem poucos subsídios teóricos sobre tal temática e também temem que possam ter dificuldades em trabalhar a questão ou lidar com situações que envolvem as relações raciais depois de formados. Eles também concordaram com o relato de uma das mães entrevistadas acerca do despreparo dos professores para trabalharem com a questão e o medo que estes possuem de cometerem equívocos que possam sugerir que estão sendo racistas.

\footnotetext{
Na escola não trabalham não (...) É porque é muito difícil você colocar isso hoje em dia porque você não pode dizer exatamente: fulano é negro ou fulano é preto como a gente falava quando era criança: Ah aquele menino é pretinho, hoje em dia a pessoa tem até medo porque pode caracterizar racismo, mas é bem difícil de se trabalhar, você focar na questão do negro, do branco, do pardo, porque as vezes a professora olha e fala não você é negra, você é um pouco mais morena e daí você chega e fala em casa: Mãe eu sou negra!" "O que? A professora está te chamando de neguinha? Vou lá conversar porque isso é racismo. Depende da família, da aceitação da família... (Maria, 48 anos)
}

Em outros casos, as mães entrevistadas indicam a dificuldade das crianças negras em se relacionarem com outras crianças e aconselham seus filhos a não criarem confusão na escola, tentando levar as crianças a aceitarem a situação, incutindo nelas a ideologia de que todos são iguais ou utilizando critérios religiosos na figura de algo divino que considera todos como filhos de Deus.

(...) daí as professoras são bem né, bem gentis e tudo, mas em relação a racismo, sempre tem né, todo lugar tem, e minha filha já teve problema com racismo, daí em casa eu falo pra ela pra lidar normalmente né, eu falei: Filha, não adianta você brigar, "Oh, mãe tem hora que eu não aguento". Mas eu falei: filha, nós todos somos filho de Deus. Pode ser branco, pode ser negro, pode ser azul, amarelo, todos tem que ter respeito" (Marialva, 47 anos) 
A ênfase central do trabalho trazia a questão de como as famílias lidavam com a questão da cor/raça na socialização de suas crianças ou como tratavam o tema em casa. Desse modo, foi considerado como pano de fundo os dados trazidos pelos estudos de Cavalleiro (2000) sobre o silenciamento nos lares das famílias negras com relação a tal temática que, indica que:

[...] o silêncio, ali reinante, quer acalentar, proteger do sofrimento que sabemos, irá ao seu encontro. Assim, a família protela, por um tempo maior, o contato com o racismo da sociedade e com as dores e perdas dele decorrentes, 'silencia' um sentimento de impotência ante o racismo da sociedade que se mostra hostil e forte 'silencia' a dificuldade que se tem em se falar de sentimentos que remetem ao sofrimento. 'Silencia' o despreparo do grupo para enfrentamento do problema, visto que essa geração também apreendeu o silêncio e foi a ele condicionada na sua socialização. (CAVALLEIRO, 2000, p. 100)

A discussão desta questão levou os estudantes a se depararem com respostas variadas que de alguma forma demonstram algumas mudanças ocorridas desde a realização do estudo supracitado por Cavalleiro (2000). As famílias entrevistadas demonstram entender que o diálogo com os filhos é necessário na dinâmica diária do lar e suas práticas educativas parecem refletir isso.

Falo com ela quase que todos os dias. Porque eu estou preparando ela pra um... porque... por ela ser afro descendente eu preparo ela todos os dias pra uma possível cena de racismo, porque eu acredito que eu preparando ela, não vai chocar quando acontecer... se acontecer... não vai chocá-la, porque ela vai falar... ela vai lembrar de que aquilo infelizmente está dentro da sociedade. Isso vai ajudar pra ela lidar de uma forma mais tranquila. Então falo quase que diariamente. (Teka, 35 anos)

A maioria das famílias dizia ter conversas esporádicas com as suas crianças sobre diferenças étnicas e raciais. A questão do fenótipo (cor, tipo de cabelo, etc.) demonstrou ser algo tratado de forma clara entre mães e filhos e filhas em uma prática educativa assistemática e informal sobre a questão, como no relato seguinte:

Ela sente diferença no cabelo dela, por exemplo, ela pergunta por que o cabelo dela é diferente. E aí todos os dias eu explico que cada pessoa nasce de um jeito, que ela não é melhor, que ela não é pior... que tem gente que é branca, tem gente que é marrom, tem gente que é japonês... e assim ela vai sempre perguntando:

"Mamãe, aquela ali é diferente, né? Mamãe, aquela ali é diferente, né?". Desse jeito... (Teka, 35 anos)

Os relatos também mostraram que algumas estratégias são criadas intuitivamente pelas famílias para lidar com a questão étnico-racial com suas crianças, ainda quando são bem pequenas. A ajuda cotidiana nas atividades triviais e nas brincadeiras apareceu como momento importante para que os adultos pudessem falar sobre o assunto.

(...) começa da hora de fazer um desenho: Ah eu vou pintar, vou desenhar o João. Bom, vamos desenhar João, mas de que cor que vamos pintar? Ai ele falou assim: Mãe, eu sou branquinho né? A primeira vez que ele falou. Eu falei, não filho você é negro, aí ele: eu sou negro? Eu falei é, pinta de preto que você é pretinho, você não é o pretinho da mãe? Ai eu comecei desde o primeiro ano de vida (Maria, 48 anos) 
Outras mães apontaram a dificuldade em se fazerem entender, já que as crianças desde pequenas já trazem questões sobre raça/cor de suas incursões pelo mundo social, sobretudo vivida com outros atores do ambiente escolar.

(...) eu já conversei com ele várias vezes, mais talvez é difícil a compreensão dele pelo fato de ser uma criança e não entender por que isso acontece às vezes só com ele e com os demais "coleguinhas" não. Quando converso com ele a maioria das vezes me faz questionamentos como já citei do cabelo e da cor, mais ai eu falo pra ele que Deus fez assim e que temos que aceitar (...). (Rosangela, 32 anos)

As práticas educativas familiares, recorrentemente, ocorrem sem nenhum planejamento prévio e envolvem todos os membros da família, demonstrando nível de complexidade e envolvimento afetivo dos envolvidos. Irmãos mais velhos, assim como pais, mães, tios e tias dentre outros componentes da família dialogam com a criança dada a oportunidade de tocarem na questão, como afirma a entrevistada Suzi:

\begin{abstract}
Embora todos aqui em casa estejam sempre dialogando com ele, ele ainda não entende muito destas questões de preconceito, discriminação. Então quando percebo que ele sofre alguma rejeição, não comento com ele. Acho que a criança deve receber informações sobre as diferenças étnicas a partir dos seis anos de idade. Primeiro em casa e a escola reforçando. (Suzi, 48 anos)
\end{abstract}

Embora as famílias tenham dito que conversam com seus filhos sobre a temática relacionada a raça/cor os relatos tenderam algumas vezes à uma aparente "fuga" presente nas falas de algumas entrevistadas ao tratar da temática com suas crianças. Em alguns relatos, a questão racial acaba envolta numa nebulosa em que todas as diferenças humanas são trazidas para conduzir a conversa que supostamente poderia trazer sofrimento para as crianças. Como exemplo, evocamos o relato de uma mãe que diz: “(...) meu filho mais velho é meio gordinho e ele fala que algumas crianças chamam ele de gordinho, eu falo para ele não ligar e falo pra ele que ele é gordinho porque come bem não passa fome. " (Simone, 25 anos).

Em outras falas, a questão da deficiência na escola associada à cor/raça emergem: .

As vezes eu falo, Ela fala "ah esta andando de cadeira de rodas"... é porque ela é especial né , aconteceu um acidente né, eu nunca cheguei assim pra falar sobre isso também, mas eu acho que até ela mesma uma vez ela falou que não queria ser negra. Ela mesma estava tendo preconceito com ela. (Simone, 25 anos)

Embora tais relatos tendem a evidenciar a negação do racismo por essas famílias, parece comum que as pessoas apontem que o fenômeno da discriminação de pretos e pardos no Brasil não envolva necessariamente a categoria raça e sim as diferenças entre classes sociais. Segundo autores como Schucman (2010) o racismo em nosso país foi historicamente negado pela alegação de que tal preconceito era algo ligado a classe, baseado no pressuposto de que negando a ideia da existência das raças seria possível negar o racismo, de tal modo que a discriminação de cor não poderia ser interpretada como discriminação racial.

Nessa perspectiva, a negação das famílias com relação a questão de discriminação racial dos filhos na escola é demonstrada pelos relatos que tendem a mudar o foco do preconceito de cor/raça pelo preconceito de classe social. Defendem a ideia de que são pobres e por isso são discriminados, como afirma uma das entrevistadas: "A única coisa que eu

\begin{tabular}{l|l|l|l|l|l|l} 
(C) ETD - Educ. Temat. Digit. & Campinas, SP & v.18 & n.3 & p.690-709 & jul./set.2016 & ISSN 1676-2592
\end{tabular}


aprendi e, que venho trazendo isso desde a minha mãe e passo para eles é que infelizmente não é só pela cor, a gente que é pobre a gente tem que fazer a diferença, tem que se esforçar bastante (...) (Silvia 42 anos). Os relatos sobre os diálogos com as crianças também giram em torno de um "todos somos iguais", tentando tirar o foco da diferença, num processo de fuga daquilo que é doloroso, quando o reconhecimento de que ser diferente poderá implicar em sofrimento para os filhos, com as seguintes declarações: "Sempre digo pra ele: Meu filho você é negro e isso não muda em nada na sua vida. Você pode fazer tudo o que todos fazem, por que todos somos iguais!" (Suzi, 48 anos) e (...)Devemos falar desde sempre. Para a criança já crescer sabendo que somos todos iguais, independente da nossa cor . (Lúcia, 48 anos)

Com a análise dessas falas exploramos a ideia de que as práticas educativas familiares acontecem sem um planejamento específico e envolvem saberes que embora não sejam sistematizados "são o resultado de uma aprendizagem social transmitida de geração para geração; manifestam-se em procedimentos e estratégias de ação e são carregados de ideologia (...)" (SZYMANKY, 2004, p. 13). Tais ações são de extrema complexidade, comportam ambivalência e uma gama de disposições afetivas, já que envolvem todos os membros da família, com o objetivo de preparar as crianças e jovens para a vida no mundo social. Desse modo, quando se fala em práticas educativas que focam a educação das relações étnicoraciais, refere-se às ações e estratégias que visam orientar as vivências sociais realizadas no contato com o outro. Tais práticas podem ter um objetivo final em um processo de ensino e aprendizagem, realizadas a partir de um simples diálogo, ou podem ainda, ocorrer nas relações triviais e cotidianas em que, na maioria das vezes, as crianças não se dão conta de que estão sendo educadas (MARTINS; SZYMANSKI, 2006).

Nessa direção, outro elemento que apareceu fortemente marcado nos relatos das famílias entrevistadas, diz respeito ao cabelo como símbolo da identidade negra. Como na pesquisa de Gomes (2003) a identidade negra tem seu suporte na cor e no cabelo crespo que pode ser visto como um forte ícone identitário e muitas vezes, símbolo de inferioridade. $\mathrm{O}$ cabelo da criança negra implica na maneira como ela se vê e é reconhecida na relação com outro, pois é um dos elementos mais visíveis e destacados do corpo. "Em todo e qualquer grupo étnico ele é tratado e manipulado, todavia a sua simbologia difere de cultura para cultura. Esse caráter universal e particular do cabelo atesta a sua importância como símbolo identitário" (p. 174). Não foi por acaso que o cabelo apareceu com destaque nos depoimentos analisados, como os de Néia:

(...) Eu procuro, estudo e vou atrás sobre isso, esse final de semana mesmo eu levei ela numa feira que chama "Feira do Encrespa", que é pra mostrar cabelo afro, cabelo duro, cabelo encrespado, que é lindo, que nós somos lindas, pra ela sempre ter orgulho" (Néia, 38 anos).

Em alguns espaços como os das famílias, ou de grupos de militância o cabelo pode ser um importante fator de construção e tomada de consciência da identidade negra. Há famílias, que por mais apelo da mídia para que os cabelos sejam alisados, tentam arduamente mudar essa ideia junto as suas crianças, como afirma uma das depoentes quando diz que: "Amamos

\begin{tabular}{l|l|l|l|l|l|l} 
(C) ETD -Educ. Temat. Digit. & Campinas, SP & v.18 & n.3 & p.690-709 & jul./set.2016 & ISSN 1676-2592
\end{tabular}


o cabelo dela que é... que por ela ser afro descendente, a gente acha o cabelo dela lindo, então amamos e incentivamos que ela use cachos e incentivamos que ela se assuma do jeito que ela é" (Teka, 35 anos).

A discussão sobre o cabelo foi marcada por várias falas dos entrevistados que defendiam o direito da menina negra em alisar os cabelos, enquanto alguns defendiam que deveriam ser preservados em sua essência. Alunas negras que tinham alisado os cabelos, afirmavam que não pretendiam negar as suas raízes, mas buscavam facilitar o dia a dia, já que o cuidado com os cabelos crespos era muito trabalhoso, como afirmou uma das entrevistadas:

Hoje em dia com a tecnologia, a gente muda, acaba transformando tudo, minhas filhas gostam do cabelo liso, mas sempre sabendo que nosso cabelo, é um cabelo crespo, um cabelo duro até por isso elas preferem, por ser mais prático estar com um cabelo alisado quimicamente, mas temos sim a noção que nosso cabelo é um cabelo afro (...). (Silvia 42 anos)

As famílias ainda foram questionadas sobre a influência da televisão na educação da criança negra e a maioria respondeu que percebe a marcante exclusão do negro nos programas televisivos. Acreditam que a televisão é um veículo que de fato pode interferir na formação da identidade das crianças, mas algumas dizem que nos últimos anos parecer estar havendo uma mudança na forma como os produtos das redes de televisão estão mostrando a população negra.

\begin{abstract}
A mídia ela conduz o ser humano, tanto que agora, se vocêfor ver, você já vê uma Barbie morena, antes não tinha, então agora já tem bonecas morenas, bonecas negras, já tem boneca gordinha, antes a mídia só mostrava a Barbie alta, loira, de cabelo liso. Agora não, então quer dizer, a mídia, ela já começou também a mudar um pouco, antes você não via um ator de novela das oito negro, ou era empregado ou era escravo, agora não, agora a mídia já está colocando... É pouco ainda, muito pouco, mas já está caminhando! (Néia, 38 anos)
\end{abstract}

Famílias também podem utilizar a televisão como um meio de educar as suas crianças, quando aproveitam o "gancho" de um programa ou uma notícia para conversar com suas crianças como elucida este relato:

Eu quase não assisto televisão porque influencia e muito no comportamento e na educação e, reforça demais o preconceito racial. Mas quando acompanho algum noticiário com este tipo assunto, logo falo pros meninos que não quero que eles repitam estas más ações. (Suzi, 48 anos)

Com relação à escolha de brinquedos para as crianças, houve vários relatos sobre a existência no mercado de bonecas negras e objetos específicos direcionados aos filhos das famílias negras, contudo, ainda parece difícil adquirir brinquedos específicos que possam auxiliar na formação da identidade das crianças negras. Além disso, as crianças parecem se recusar a brincar com bonecos negros.

Nunca dei bonecos pretos pra ele. Mas quando pergunto se ele gostaria de ter algum, ele me diz que não quer porque são feios e ninguém tem boneco preto. Aah, também são brinquedos muito difíceis de encontrar, principalmente para meninos. (Suzi, 48 anos) 
A boneca Barbie apareceu de modo significativo nas entrevistas. Com o ideal de beleza pautado em padrões americanos ou europeus, tal boneca tem um fenótipo que está longe de se assemelhar ao da mulher brasileira. Sabe-se que com o passar do tempo, foram produzidas algumas Barbies negras, no entanto, elas apresentam as mesmas características da Barbie branca. Nas falas das mães aparece uma defesa para que as meninas façam escolhas por bonecas negras, mas a mídia e a indústria de brinquedos não incentivam essa aquisição pelas famílias produzindo e divulgando uma quantidade muito maior de bonecos brancos do que negros.

\begin{abstract}
Eu falo pra ela da diferença das pessoas... falo pra ela, quando ela vai escolher um brinquedo, e eu vejo que ela está escolhendo só, por exemplo, bonecas loiras, Barbies... eu sempre falo pra ela assim: "Vamos pegar uma boneca moreninha? Vamos pegar uma Monster moreninha? Vamos? Que é igual nós?”, pra ela... pra ela ver que é legal também. E ela tem bonecas negras. Mas como a maioria... como a indústria não ajuda muito, então a maioria é branca do olho azul, e ela acha bonito branca do olho azul. É Fato. (Teka, 35 anos)
\end{abstract}

Esse foi um dos temas que chamou muito a atenção dos estudantes entrevistadores. Muitos deles já trabalhavam ou faziam estágio na educação infantil e trouxeram experiências de suas escolas em que há pouco ou nenhum boneco negro. Nesses momentos de trocas entre professores e estudantes, a fundamentação teórica para as discussões a respeito dessa temática foi tecida por autores como Vygotsky (1995) que ressalta a importância do brinquedo no desenvolvimento a formação da criança. Contudo, foi importante trazer pesquisas mais atuais que investigam os efeitos das imagens das bonecas na constituição das subjetividades infantis e na formação da identidade da criança negra como no trabalho de CECHIN e SILVA (2014).

\title{
5 OS RELATÓRIOS FINAIS: A EXPERIÊNCIA NA PERCEPÇÃO DOS ESTUDANTES
}

Como fechamento do semestre, foi possível analisar, a partir dos relatórios dos estudantes, o impacto das ações de iniciação à pesquisa, assim como o da temática discutida na formação de cada um dos participantes do grupo. Foi possível perceber na maioria dos relatos dos alunos que a formação inicial de professores necessita de um currículo específico que possa compreender as questões referentes às relações étnico-raciais de forma ampla. Os estudantes questionaram porque as universidades não incluem disciplina específica sobre o tema, sobretudo em respeito da Lei 10.639/2003 e de suas respectivas Diretrizes Curriculares Nacionais, bem como da Lei 11.645/200812 que estabelece à obrigatoriedade do ensino sobre História e Cultura Afro-Brasileira e Indígena. Os relatos dos estudantes apontam para essa necessidade.

A experiência da participação na PPP (Práticas Pedagógicas Programadas) certamente foi muito enriquecedora, primeiramente por nós estudantes de Pedagogia não termos uma Unidade Curricular fixa que trate de questões étnicoraciais em nossa grade, sendo que é um tema e uma realidade presentes e que precisam ser discutidos e trabalhados cada vez mais. (Rosana, aluna branca) 
Houve por unanimidade a concordância dos alunos sobre a necessidade de maior discussão sobre a temática em cursos de formação inicial e continuada de professores. Defenderam que é urgente que se possa sepultar o senso comum de que essa questão seja restrita apenas à educação básica. Para eles, seria importante que as instituições de ensino superior, sobretudo aquelas preocupadas com a formação de professores incluíssem em seus programas disciplinas e conteúdos que pudessem dar conta da formação para a Educação das Relações Étnico-raciais, assim como a interconexão das diversas áreas de conhecimento.

Outro aspecto bastante relevante na opinião expressa dos estudantes, diz respeito às diversas formas de iniciação à pesquisa científica que podem estar presentes nos cursos de formação de professores. O preparo dos estudantes para o trabalho investigativo, possibilitando o acesso às metodologias de pesquisa e um olhar mais crítico para a realidade também aparece na escrita dos relatórios dos alunos:

As experiências de preparar e fazer uma entrevista também foram novas pra mim e de grande valor, pois não imaginava que uma simples frase dita em uma conversa gravada, depois, ao ser analisada renderia tantos assuntos. (Rosangela/branca)

A experiência de trabalho de campo e o "treino" para a realização de entrevistas foi de grande significado para muitos alunos. Descobriram as dificuldades encontradas por pesquisadores para conseguir participantes para a pesquisa e a delicadeza no tratamento de determinados assuntos com pessoas que voluntariamente se disponibilizam a falar de suas vidas e sobre assuntos tão íntimos e complexos.

Sobre a entrevista em si, foi um grande choque saber que o preconceito está tão impregnado na sociedade, a ponto de uma pessoa negra se acostumar e chegar a dizer que isso é "normal", (...) Já de começo, foi dificil abordar uma pessoa negra para fazer a pesquisa sobre questões étnico-raciais, ainda mais que no meu caso mesmo eu sendo de descendência negra tenho a pele mais "clara". Isso foi algo que me incomodou um pouco, temos a impressão de que a pessoa se sente coagida, é ate certo ponto compreensível. A entrevista por si só já é uma forma de invasão, ainda mais com temas que relembram situações negativas que não são fáceis de falar (Jussara/parda).

Os alunos também apontaram avanços em termos teóricos e o despertar para discussões mais demoradas sobre o tema. Alguns se identificaram tanto com a temática que apostam em suas pesquisas individuais sobre a questão, como afirma Marcela: "Gostaria muito de continuar a discutir e este tema, e possivelmente, desenvolvê-lo em meu TCC." (Marcela, aluna negra), ou ainda:

É difícil avaliar em números algo que vai para além de uma pesquisa acadêmica, são estudos e reflexões da vida em sociedade, uma sociedade que infelizmente tem seus preconceitos e violências perpetuadas. As leituras para essa pesquisa, as mídias indicadas, as palavras e expressões durante a entrevista, cada um desses fatores, pedem por uma interferência, por mais pesquisas, artigos, por um despertar coletivo para esta questão. (Jussara/Parda)

O trabalho de campo e as discussões realizadas em sala de aula também contribuíram de forma visível para a construção das próprias identidades dos alunos do curso, já que 
muitos, inicialmente declararam nunca terem discutido sobre a questão, apesar de serem pardos e negros. As descobertas foram muitas e a intervenção ocorreu de forma impactante, ainda que esse não fosse o objetivo principal do trabalho.

$\mathrm{Na}$ entrevista, encontrei identificação nas palavras da minha entrevistada em alguns acontecimentos e fatos por ela relatados. De fato, na escola me descobri negro, pobre e bastardo, em uma sala com muitas crianças brancas e, aos meus olhos na época, ricas (...) Houve silêncio de minha família nordestina que, em São Paulo desde a década de 1970, acabou perdendo suas raízes culturais e, naturalmente, se descaracterizando ao perder a identidade. Consequentemente, houve meu silêncio até a quinta série, onde surge uma resposta violenta (...). Aí me descubro negro, paulistano descendente de nordestino e pertencente a uma classe social que precisa de melhores condições em sua existência. A valorização da raça e das origens se dão neste momento de forma crítica, artista e politizada. (Claudio/negro)

Para outros estudantes, como Marcela, que apontou questões bastante pertinentes exercendo um grande poder no grupo apesar de tímida, também foi essencial ter participado do processo.

\begin{abstract}
Minha experiência nesta disciplina foi um tanto satisfatória e construtiva, pois, embora já tivesse discutido um pouco à respeito das políticas étnico-raciais, (mesmo que superficialmente), esta experiência de pesquisa de campo ampliaram minhas ideias e pretensões, e me fez reafirmar ainda mais, o orgulho que tenho de ser negra, e o quanto preciso lutar pelo meu espaço, e ajudar a construir a trajetória dos meus. Durante nosso diálogo, consegui estabelecer algumas relações com as leituras propostas ao longo dos nossos encontros, e compreender mais claramente a grande influência da família e mais ainda do papel da escola na realidade da população negra que é socialmente desfavorecida. (Marcela/negra)
\end{abstract}

De um modo geral, não restam dúvidas sobre a potencialidade de ações e projetos como esses para o desenvolvimento geral de professores em formação. Todos os relatos apontaram a disciplina como elementar para a construção de um pensamento mais crítico sobre a questão. Muitos estudantes se identificaram com as famílias entrevistadas, assim como questionaram muitas falas e, desenvolveram a partir das entrevistas reflexões que possibilitarão um trabalho mais seguro e respeitoso quando assumirem suas salas de aulas e tiverem contato com seus alunos brancos e negros, assim como em suas vidas cotidianas.

\title{
6 CONSIDERAÇÕES FINAIS
}

As experiências de pesquisa e de discussão de uma temática tão atual favoreceram o estabelecimento de momentos de grandes aprendizagens nessa disciplina, que apesar de ocupar somente um semestre letivo com encontros semanais foram de muita intensidade e trocas interpessoais. Tais momentos inspiraram estudantes e futuros professores a exporem suas ideias de modo claro, desmistificando os preconceitos e os temores de se falar e se pensar aspectos relacionados à população negra, embora essas discussões ainda podem ser consideradas como temas tabus no ambiente e nas práticas escolares e acadêmicas. 
Compreender as vicissitudes que envolvem o trabalho da família negra na difícil tarefa de educar seus filhos para a construção de suas identidades, também foi um processo bastante enriquecedor. Além da experiência de pesquisa, do olhar respeitoso pelo modo de pensar expresso na fala voluntária do outro, os estudantes foram além, descontruindo modelos lineares e cristalizados historicamente construídos sobre a temática das relações étnico-raciais e, sobretudo, sobre a população negra que vem ao longo do tempo passando por tantos infortúnios nos processos excludentes do mundo escolar, do trabalho, da saúde, dos bens e serviços e da sociedade mais ampla.

O trabalho de iniciação a pesquisa com os estudantes também rendeu muitos frutos. Os dados relativos às entrevistas proporcionaram com riqueza de detalhes o que pensam essas famílias sobre a educação para as relações étnico-raciais tanto no ambiente do lar como naqueles nos quais mães, pais e irmãos não estão diretamente presentes. Os resultados do trabalho de campo apontam para indícios de que a família negra atual tem se preocupado mais com os elementos que envolvem sua raça/cor e tem buscado orientar seus filhos para o enfrentamento de situações de violência presentes nos processos discriminatórios. As falas da maioria das famílias giraram em torno de práticas educativas preocupadas com a socialização e com o preparo de suas crianças para uma sociedade em que o mito da democracia racial vem progressivamente caindo por terra. Tais relatos apontam para a urgente necessidade de repensarmos as práticas educativas de professores da educação básica que atuam na socialização secundária e escolarização de crianças pequenas. Essa experiência atingiu seu objetivo de mostrar aos alunos em formação inicial para o exercício da docência, a importância de compreenderem o papel das famílias negras e do trabalho sobre a temática que viverão em suas práticas enquanto professores.

De um modo geral, os estudantes puderam discutir, a partir da fundamentação teórica e da pesquisa de campo, aspectos importantes para a reflexão e formação do professor crítico. A partir dos relatórios e análises individuais, os alunos puderam registrar o quanto se envolveram com a temática, enquanto outros não se intimidaram em mostrar verbalmente e em seus relatórios escritos, as importantes descobertas que fizeram acerca de suas próprias identidades.

Enfim, a experiência com a disciplina mostra que pensar formas de inserir alunos no mundo da pesquisa científica atrelado às temáticas que farão parte de seus campos de atuação é tarefa urgente dos cursos de formação inicial de professores. O trabalho de pensar as políticas públicas de promoção de igualdade racial em consonância com as práticas cotidianas de educadores representa fator necessário para o desenvolvimento de uma escola menos excludente. Outro fator que leva a reflexão sobre a construção de espaços mais democráticos, diz respeito à iniciativa de interlocução das famílias com todos os atores escolares em busca de práticas educativas mais produtivas e respeitosas na formação de nossas crianças. 


\section{REFERÊNCIAS}

ARAUJO, Lucimeire Carvalho; CAMARGO, Climene Laura. Reflexões sobre a família de indivíduos negros e os desafios do seu quotidiano. Revista Baiana de Saúde Pública, Salvador, BA, v. 38, n. 03, p. 725-737. 2015. Disponível em: 〈http://goo.gl/z0luQC $\rangle$. Acesso em: 29 jul. 2015. ISSN 2318-2660.

BERGER, Peter; LUCKMANN, Thomas. A construção social da realidade. 5.ed. Petrópolis: Vozes, 1983. 247 p.

CASTRO, Mary Garcia; ABRAMOVAY, Miriam. Relações raciais na escola: reprodução de desigualdades em nome da igualdade. Brasília: UNESCO, 2006. 370 p. Disponível em: < http://goo.gl/VsI4B>. Acesso em: 29 jul. 2015.

CAVALLEIRO, Eliane. Do silêncio do lar ao silêncio escolar: racismo, preconceito e discriminação na educação infantil. São Paulo: Contexto, 2000. 110 p.

CECHIN, Michelle Brugnera Cruz; SILVA, Thaise da. Uma bailarina pode ser negra? Crianças, bonecas e diferenças étnicas. Estudos e Pesquisas em Psicologia, Rio de Janeiro, RJ, v. 14, n. 02, p. 610-627. 2014. Disponível em: 〈http://goo.gl/M2yMrk〉. Acesso em: 29 jul. 2015. ISSN 1808-4281.

CIAMPA, Antonio Carlos. A estória do Severino e a história da Severina. São Paulo: Brasiliense, 1987. 248 p.

FERREIRA, Ricardo Frankllin; CAMARGO, Amilton Carlos. As relações cotidianas e a construção da identidade negra. Psicologia Ciência e Profissão, Brasília, DF, v. 31, n. 02, p. 347-389. 2011. Disponível em: 〈http://goo.gl/pNYg3e>. Acesso em: 29 jul. 2015. ISSN 1414-9893.

GEBARA, Tânia Aretuza Ambrizi; GOMES, Nilma Lino. Gênero, família e relações étnicorraciais: um estudo sobre as estratégias elaboradas por mulheres negras e brancas provedoras nas relações que estabelecem com a educação de seus filhos (as). Revista Fórum Identidades, Aracaju, SE, v. 10, n. 10. jul./dez. 2011. Disponível em: 〈http://goo.gl/cgfrq9>. Acesso em: 29 jul. 2015. ISSN 1982-3916.

GOMES, Nilma Lino. Sem perder a raiz: corpo e cabelo como símbolos da identidade negra. São Paulo: Autêntica, 2006.

GOMES, Nilma Lino. Educação, identidade negra e formação de professores/as: um olhar sobre o corpo negro e o cabelo crespo. Educação e Pesquisa, São Paulo, SP, v. 29, n. 1, p. 167-182. jan./jul. 2003. Disponível em: 〈http://goo.gl/cxI3HE>. Acesso em: 29 jul. 2015. ISSN 1678-4634.

LEWIS, Liana; NASCIMENTO; Emanuele Cristina Santos do. Crianças e negociações raciais a partir da telenovela Fina Estampa. Estudos de Sociologia, Recife, PE, v. 02, n. 19. 2013. Disponível em: 〈http://goo.gl/MH7EiE〉. Acesso em: 29 jul. 2015. ISSN 1415-000X. 
MARTINS, Edna; SANTOS, Alessandro de Oliveira dos; COLOSSO, Marina. Relações étnico-raciais e psicologia: publicações em periódicos da SciELO e Lilacs. Revista Psicologia: Teoria e Prática, v. 05, n. 03, p. 118-133. set./dez. 2013. Disponível em: < http://goo.gl/Nb8Kty>. Acesso em: 29 jul. 2015. ISSN 1980-6906.

MARTINS, Edna; GERALDO, Aparecida das Graças. A influência da família no processo de escolarização e superação do preconceito racial: um estudo com universitários negros.

Revista Psicologia Política, São Paulo, SP, v. 13, n. 26, p. 55-73. jan./abr. 2013. Disponível em: 〈http://goo.gl/7KTSbM>. Acesso em: 29 jul. 2015. ISSN 1519-549X.

MARTINS, Edna; SZYMANSKI, Heloisa. Brincadeira e práticas educativas familiares: um estudo com famílias de baixa renda. Interações, São Paulo, SP, v. 11, n. 21, p. 143-164. jan./jun. 2006. Disponível em: 〈http://goo.gl/gXfer7>. Acesso em: 29 jul. 2015. ISSN 14132907.

OSÓRIO, Rafael Guerreiro. O sistema classificatório de cor ou raça do IBGE. Brasília: IPEA, 2003. Disponível em: 〈http://goo.gl/Qz3JaE>. Acesso em: 29 jul. 2015.

PAIVA, Geraldo José de. Identidade psicossocial e pessoal como questão contemporânea. Psico, Porto Alegre, RS, v. 38, n. 01, p. 77-84. jan./abr. 2007. Disponível em: 〈http://goo.gl/huaWcB >. Acesso em: 29 jul. 2015. ISSN 1980-8623.

PINTO, Márcia Cristina Costa; FERREIRA, Ricardo Franklin. Relações raciais no Brasil e a construção da identidade da pessoa negra. Revista Pesquisas e Práticas Psicossociais, São João Del-Rei, MG, v. 09, n. 02, p. 256-266. jul./dez. 2014. Disponível em: <http://goo.gl/EPytKs >. Acesso em: 29 jul. 2015. ISSN 1809-8908.

PIZA, Edith; ROSEMBERG, Fúlvia. Cor nos censos brasileiros. Revista USP, São Paulo, SP, n. 40, p. 122-137. dez. 1998/fev. 1999. Disponível em: 〈http://goo.gl/qOMJiZ〉. Acesso em: 29 jul. 2015. ISSN 2316-9036.

SCHUCMAN, Lia Vainer. Racismo e antirracismo: a categoria raça em questão. Revista Psicologia Política, São Paulo, SP, v. 10, n. 19, p. 41-55. jan. 2010. Disponível em: <http://goo.g1/BSKw1X>. Acesso em: 29 jul. 2015. ISSN 1519-549X.

SILVA, Petronilha Beatriz Gonçalves e. Diretrizes Curriculares Nacionais para a Educação das Relações Étnico-Raciais e Para o Ensino de História e Cultura AfroBrasileira e Africana. Brasília: MEC, 2004. Disponível em: 〈http://goo.gl/GEpxOl>. Acesso em: 29 jul. 2015.

SZYMANSKI, Heloisa. Práticas educativas familiares: a família como foco de atenção psicoeducacional. Revista Estudos de Psicologia, Campinas, SP, v. 21, n. 02, p. 05-16. mai./ago. 2004. Disponível em: 〈http://goo.gl/9SOjg8>. Acesso em: 29 jul. 2015. ISSN 1982-0275.

VERRANGIA, Douglas. Educação científica e diversidade étnico-racial: o ensino e a pesquisa em foco. Interacções, Lisboa, v. 10, n. 31, p. 02-27. 2014. Disponível em: <http://goo.gl/tyFBRw>. Acesso em: 29 jul. 2015. ISSN 1646-2335. 
VYGOTSKY, Lev Semionovitch. Historia del desarrollo de las funciones psíquicas superiores. Obras escogidas. Madrid: Visor; MEC, 1995. Disponível em:

<http://goo.gl/HNg1PM>. Acesso em: 29 jul. 2015.

\section{EDNA MARTINS}

Doutora em Educação - PUCSP, São Paulo, SP - Brasil

Professora Adjunta - Departamento de Educação

Universidade Federal de São Paulo - UNIFESP

Guarulhos, SP - Brasil - E-mail: emartinsunifesp@gmail.com.

RENATA MARCÍLIO CÂNDIDO

Doutora em Educação - USP, São Paulo, SP - Brasil.

Professora Adjunta - Departamento de Educação

Universidade Federal de São Paulo - UNIFESP

Guarulhos, SP - Brasil - E-mail: remarcilio@gmail.com.

Recebido em: 29/07/2015

Aprovado para publicação em: 02/04/2016.

\section{Como citar este documento:}

MARTINS, Edna; CANDIDO, Renata Marcilio. Práticas educativas de famílias negras e relações étnico-raciais: uma experiência em formação de professores. ETD - Educação Temática Digital, Campinas, SP, v. 18, n. 3, p. 690-709, jul. 2016. ISSN 1676-2592. Disponível em:

<http://periodicos.sbu.unicamp.br/ojs/index.php/etd/article/view/8638937>. Acesso em: 30 ago. 2016.

doi:http://dx.doi.org/10.20396/etd.v18i3.8638937. 